\title{
CriançAS, JOVENS E NOTÍCIAS: UMA REVISÃo SISTEMÁtiCA DA Literatura a PARTIR dA Communication AbSTRACTS
}

\author{
Joana Fillol \\ Centro de Estudos de Comunicação e Sociedade, Instituto de Ciências Sociais, Universidade do Minho, Portugal \\ Sara Pereira \\ Centro de Estudos de Comunicação e Sociedade, Instituto de Ciências Sociais, Universidade do Minho, Portugal
}

\begin{abstract}
Resumo
Apesar de terem a sua raiz na Medicina e de serem mais frequentes nas Ciências Naturais, as revisões sistemáticas da literatura podem revestir-se de grande utilidade, também, nas Ciências Sociais, nomeadamente quando se pretende empreender um estudo que identifique e mapeie o que foi alvo de interesse por parte dos cientistas num determinado campo. Neste artigo, a técnica de revisão sistemática de literatura foi aplicada à principal base de dados no campo da Comunicação, a Communication Abstracts, com o intuito de perceber quem, quando e onde tem estudado a relação entre crianças e/ou jovens e notícias e qual tem sido o ângulo privilegiado pela investigação. Uma amostra de 146 títulos e resumos de artigos foi analisada. Os resultados revelam que os estudos de receção e de representação dominam a investigação no tema em apreço, sendo pouco expressivos os estudos sobre a produção e praticamente residuais aqueles que se debruçam sobre a mediação parental e as preocupações éticas dos jornalistas quando cobrem acontecimentos que envolvem crianças e jovens.
\end{abstract}

crianças; jovens; notícias; jornalismo; revisão sistemática da literatura

\section{Children, young PEOple AND The News: A SySTEMATIC LITERATURE REVIEW BASEd on Communication AbSTRACTS}

\begin{abstract}
Despite having their roots in Medicine and being more frequently used in Natural Sciences, systematic reviews can also be extremely useful when it comes to the Social Sciences, namely when the aim is to conduct a study that identifies and maps the subject of interest of scientists in a given area. In this paper, a systematic literature review has been applied to the main database in the field of Communication, Communication Abstracts, as to try and understand who studied the relationship between children and/or young people and the news, when and where that happened, as well as the angle of the investigation. A sample of 146 titles and abstracts was reviewed. The findings show that most of them were reception and representation studies, whereas production studies were in much smaller number; studies on parental mediation and journalists' ethical concerns when covering events involving children and young people were practically residual.
\end{abstract}




\section{INTRODUÇÃo}

"Newton não podia ter visto o que viu sem que antes Galileu, Kepler, Descartes e outros não o tivessem precedido" (Fiolhais, 2011, s. p.). É desta forma que o físico e ensaísta português Carlos Fiolhais esmiúça, no blogue De Rerum Natura, a sugestiva metáfora dos anões sobre os ombros de gigantes, segundo a qual as descobertas realizadas por quem nos precedeu nos permitem ver mais. E ver mais longe. A ideia, atribuída originalmente ao monge medieval francês Bernardo de Chartres (e eternizada nos vitrais azuis da catedral da cidade francesa com o mesmo nome, onde os evangelistas surgem encavalitados aos ombros dos profetas), se aplicada à ciência, transmite essa visão do trabalho científico como um continuum, em que os avanços no conhecimento se fazem tendo por base as descobertas anteriores. Como tão bem se ilustra ainda nesse mesmo post: "a construção da ciência é uma pirâmide humana" (Fiolhais, 2011, s. p.).

Ora, é nesta visão cumulativa do trabalho científico que reside a importância de conhecer o estado da arte de um determinado campo antes de se empreender qualquer processo de investigação. A revisão de literatura constitui-se, assim, como a base de toda e qualquer pesquisa científica e realiza-se tanto com o objetivo de resumir o que se sabe até ao momento sobre uma determinada área de conhecimento, como de motivar novas investigações (Carver, Hassler, Hernandes \& Kraft, 2013).

Vom Brocke, Simons, Bjoern Niehaves, Bjorn Niehaves, Reimer, Plattfaut e Cleven (2009) sublinham que a importância deste trabalho assenta, nomeadamente, na procura de fontes relevantes para um determinado tópico e no contributo que essa busca dá para garantir a relevância e o rigor da investigação. Os autores recorrem a Baker (2000, citado em Vom Brocke et al., 2009) para explicar que, por relevância, se entende o evitar reinvestigar o que já se conhece, e servem-se de Hevner et al. (2004, citado em Vom Brocke et al., 2009) para especificar que o rigor advém de um uso efetivo do conhecimento já existente.

Facilitada pelas tecnologias da informação, a crescente quantidade de conhecimento científico ao dispor da comunidade veio tornar os processos de revisão de literatura cada vez mais exigentes (Best, Taylor, Manktelow \& McQuilkin, 2014; Campbell, Taylor, Bates \& O'Conner-Bones, 2018). Tornou, também, mais premente a necessidade de avaliar a qualidade dessas revisões - uma questão que não é propriamente recente. Já nos anos oitenta, Cooper (1988) notava um aumento de revisões de literatura no âmbito da Educação e da Psicologia, que associava justamente à "explosão de informação" e ao aumento de investigadores (p. 105) na área. Face a essa nova realidade, o investigador e psicólogo norte-americano manifestava preocupação com a qualidade das revisões de literatura e alertava para a necessidade de elas serem alvo de um rigoroso escrutínio, propondo uma taxonomia para as classificar, cujo objetivo era "distinguir trabalhos superiores de trabalhos inferiores" (p. 105). 
A principal desvantagem apontada às revisões de literatura tradicionais relaciona-se com a falta de um método específico que as oriente, algo que Carver et al. (2013) resumem do seguinte modo: "a falta de rigor pode influenciar os resultados ou fazer com que o investigador omita publicações relevantes, alterando a natureza das conclusões" (p. 203). Embora admitindo que as revisões convencionais podem ser válidas e interessantes, também Petticrew e Roberts (2006) alertam para o risco de uma revisão deste género poder resultar numa "revisão parcial de uma amostra de conveniência dos estudos favoritos do autor" (p. 6).

Pelo contrário, ao serem formalmente planeadas e metodicamente executadas (Staples \& Niazi, 2007), as revisões sistemáticas da literatura (RSL) parecem responder de um modo mais eficaz ao problema da arbitrariedade, na escolha da literatura a considerar, que carateriza as revisões narrativas. Como frisa Ramalho (2005), o objetivo central das RSL é precisamente o de reduzir a possibilidade de vieses, tal como se pretende em qualquer investigação. A autora realça a objetividade e a reprodutibilidade, pilares fundamentais de todo o trabalho científico, como algumas das principais caraterísticas deste género de estudos. Petticrew e Roberts (2006) apontam, ainda, outra vantagem das revisões sistemáticas, que julgam justificar a sua crescente popularidade: "fornecem um meio de lidar com a montanha de informações, ao permitir que grandes quantidades de pesquisa sejam destiladas de forma gerenciável" (p. 11).

\section{HistóRIA E LIMITAÇões DA RSL}

O desenvolvimento das RSL é geralmente situado no início dos anos 90 do século passado, com a publicação do "Evidence-based Medicine Working Group" (Boell \& Cecez-Kecmanovic, 2015). Este tipo de estudo começou, portanto, a ser usado no campo da Medicina para agregar evidências e conhecimentos que sustentassem a opção por determinados procedimentos clínicos e a adoção de determinadas políticas. Desde então, o recurso a RSL tem vindo a ser defendido por diferentes áreas do conhecimento que reconhecem e tiram partido das suas vantagens - da Engenharia de Sistemas à Psicologia, da Enfermagem à Educação. Independentemente da área científica em que se enquadrem, as RSL parecem servir propósitos muito diferentes. Trata-se, desde logo, de uma metodologia que é adotada tanto para obter uma visão panorâmica de um tema a investigar como para encontrar evidências que respondam a questões de pesquisa muito específicas. Num e noutro caso, o que se pretende é sempre obter uma síntese do trabalho anteriormente desenvolvido.

Apesar de terem a sua raiz nas Ciências Naturais, nas Ciências Sociais são vários os investigadores que têm realizado estudos com os quais pretendem evidenciar como as RSL podem ser aplicadas a este domínio científico (Campbell et al., 2018; Ramos, Faria \& Faria, 2014; Victor, 2008).

Independentemente da disciplina, nos artigos que seguem os procedimentos da RSL nota-se, frequentemente, um entusiasmo excessivo com esta técnica de pesquisa, adotada, não raras vezes, sem que se faça acompanhar por uma reflexão crítica acerca 
dela por parte dos investigadores que a elegem. Julgamos que quando se opta por empreender uma RSL é importante refletir, também, sobre as suas limitações e sobre o que se perde face a uma revisão narrativa de literatura, ou seja, uma revisão que não segue critérios rígidos e facilmente replicáveis.

No artigo "On being 'systematic' in literature reviews in IS", Boell e Cecez-Kecmanovic (2015) empreendem uma reflexão profunda sobre a RSL, questionando muitas das caraterísticas e vantagens que lhe são apontadas. Na esteira de autores como Hammersley, Hjrland ou Finfgeld-Connett e Johnson, alertam para o facto de a importação das RSL da Medicina para outras disciplinas poder conduzir a um viés empirista/positivista relativamente ao conhecimento científico. Chamam ainda a atenção para a sua adoção poder "minar o envolvimento crítico com a literatura e com o que significa pesquisar no trabalho académico" (p. 161). Sublinham, nomeadamente, a minimização do papel do investigador - da sua "interpretação, imaginação, criatividade e individualidade na seleção e julgamento dos estudos e descobertas" (p. 165).

De acordo com a visão de Boell e Cecez-Kecmanovic (2015) a realização de uma RSL não se pode substituir a uma revisão de literatura narrativa, mas, como os autores australianos também escrevem, ela pode ser útil para um tipo específico de revisão de literatura: "um meta estudo que identifica e sumariza evidência da pesquisa anterior" ( $p$. 163). Petticrew e Roberts (2006) veem a RSL como um método de pesquisa adequado para responder a perguntas específicas. Afirmam que é menos uma discussão da literatura e mais uma ferramenta científica: uma forma de olhar para os estudos como se olha para os respondentes numa pesquisa - "os resultados de um entrevistado podem dizer algo (...) mas é mais provável que alguém aprenda mais examinando os dados de todos os entrevistados, o alcance das respostas, por que variam e tentando resumi-las" (Petticrew \& Roberts, 2006, p. 15). Uma ideia que vai ao encontro da veiculada por Tranfield, Denyer e Smart (2003, p. 209): “a meta-análise oferece um procedimento estatístico para sintetizar os resultados, a fim de obter uma fiabilidade geral indisponível a partir de qualquer estudo isolado".

\section{MotivaÇÃo PARA A REALIZAÇÃo DE UMA RSL}

Confrontados com a necessidade de fazer uma revisão da literatura para identificar quem, quando e onde tem estudado a relação entre crianças e/ou jovens e notícias e qual tem sido o ângulo privilegiado pela investigação, a RSL afigurou-se como uma resposta adequada, até por não ter sido encontrado nenhum estudo semelhante. Pretendeu-se, assim, alcançar uma visão global, panorâmica, do campo a estudar: a relação entre crianças e/ou jovens e notícias.

No capítulo "Views on the news", escrito já em 2011, Hobbs, Cohn-Geltner e Landis começavam precisamente por notar que "na literatura académica sobre comunicação de massas, educação e desenvolvimento humano, poucos temas são mais marginalizados do que aquele que envolvem crianças, eventos atuais e notícias" (p. 43). Esta é uma opinião partilhada por vários autores (Buckingham, 1997; English, Barnes, Fynes-Clinton \& 
Stewart, 2019; Hobbs, Cohn-Geltner \& Landis, 2011). Apesar desta constatação, há estudos que se debruçam sobre a relação entre crianças e notícias, abordando-a sobretudo a partir da receção, da produção e da representação (Pereira, Fillol \& Silveira, 2015).

Sendo lugar-comum que as crianças não se interessam por notícias, já alguns investigadores demonstraram o contrário (Carter \& Allan, 2005; Silveira, 2019). Um outro estudo, centrado na relação das crianças do Reino Unido com o serviço noticioso para a infância da BBC, o Newsround, Carter, Messenger Davies, Allan e Mendes (2009) mostraram o contributo que as notícias podem dar para o crescimento das crianças enquanto cidadãs e como o facto de se sentirem representadas constitui um estímulo ao seu interesse pelas questões que se colocam à sociedade.

As questões a explorar nesta RSL poderão ter relevância científica no campo das Ciências da Comunicação por ajudarem a construir um panorama geral do que tem sido a investigação nesta área, identificando as tendências que se verificam, mas também as lacunas que existem no campo e que podem motivar a sua colmatação. Deste modo, este trabalho poderá interessar a investigadores que estudam o tema dos media, das crianças e dos jovens, bem como a profissionais de jornalismo e educação.

\section{Metodologia}

Conforme explicitado no início deste artigo, uma RSL deve ser formalmente planeada, envolvendo várias fases, cada uma das quais contendo uma sequência de etapas (Staples \& Niazi, 2007). Todos esses momentos devem estar previstos num protocolo estrito, que descreve os processos e métodos a serem aplicados (Boell \& Cecez-Kecmanovic, 2015; Petticrew \& Roberts, 2006), sendo este que garante a suposta transparência, objetividade e possibilidade de replicação de todo o processo. "Suposta" porque, como sublinham Boell e Cecez-Kecmanovic (2015), "a RSL confunde os "procedimentos objetivos' do processo com a objetividade dos resultados da revisão", que dependerá sempre da subjetividade dos autores que a realizem (p. 166). Neste artigo, as etapas de planeamento e análise seguidas foram adaptadas do modelo sugerido por Petticrew e Roberts (2006), autores de um guia prático para a realização de RSL em Ciências Sociais, tal como ilustrado na figura apresentada abaixo.

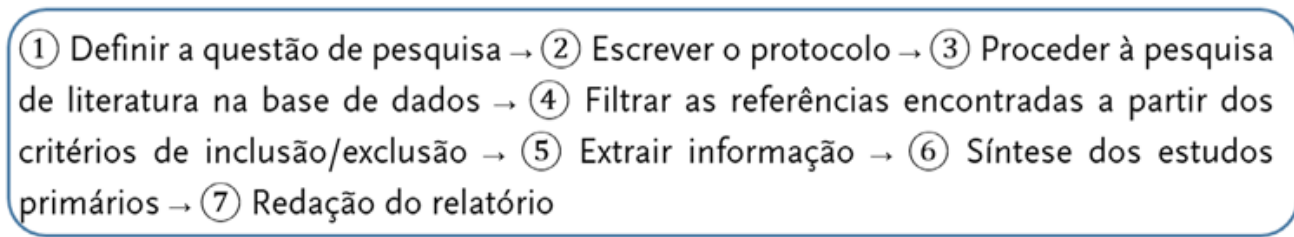

Figura 1: Etapas seguidas para a revisão sistemática da literatura (adaptado de Petticrew \& Roberts, 2006)

Para relatar a informação extraída da leitura dos resumos, inspirámo-nos no modelo seguido por Luís Pereira (2011). 


\section{Perguntas de investigação}

Tendo em mente que as questões que guiam uma RSL devem ser fechadas e ter respostas que resumam evidências (Boell \& Cecez-Kecmanovic, 2015), formulámos a seguinte pergunta de investigação:

1. Quem, quando, onde e como a relação entre crianças e/ou jovens e notícias tem vindo a ser abordada na investigação científica?

1.1. Que ângulos foram mais explorados e mais descurados?

1.2. Notam-se tendências associadas a determinados períodos temporais?

1.3. Como tem evoluído o interesse pelo tema em função do número de artigos e temáticas?

1.4. Que faixas etárias foram mais estudadas?

1.5. Que meio jornalístico foi mais estudado (imprensa, rádio, televisão, jornalismo escrito)?

1.6. Que investigadores se têm debruçado mais sobre estas questões?

1.7. Que países se dedicam mais a estudar esta matéria?

1.8. Até que ponto investigadores de países diferentes têm trabalhado em conjunto?

1.9. Que revistas publicaram mais artigos neste domínio?

1.10. Que palavras-chave foram mais utilizadas?

\section{SELEÇão dA BASE dE DAdoS}

Por norma, uma RSL propõe-se identificar todos os estudos relevantes para responder a uma pergunta específica. É, no entanto, possível levar a cabo alternativas a uma RSL completa, que podem ser úteis quando se procura mapear um tópico geral. Petticrew e Roberts (2006) designam um estudo deste tipo por "revisão rápida". Tratase de uma revisão sistemática que é, de alguma forma, restrita (a um país, a um ano, etc.). Neste caso, a revisão levada a cabo foi restringida a uma base de dados, a que mais diretamente se relaciona com a Comunicação, a área de estudo em questão.

A Communication Abstracts foi eleita por disponibilizar títulos, resumos e informação bibliográfica de artigos contidos em 240 publicações académicas indexadas na área da Comunicação, dos media de massas e de outros campos de estudo que, com eles, se relacionam intimamente. Anteriormente produzida pela SAGE, esta base de dados referencial é atualmente gerida pela EBSCO e coloca à disposição mais de 360 mil registos, datados de 1978 até à atualidade. Embora conscientes de que restringir a pesquisa a uma base de dados condiciona os resultados (Best et al., 2014; Boell \& Cecez-Kecmanovic, 2015), considera-se que, pela sua abrangência e importância, o material obtido através da Communication Abstracts constitui uma interessante amostra para um entendimento inicial do tema em estudo.

\section{FóRMula de PESQUisa E FILTROS}

Para realizar a pesquisa foram identificados dois grupos de conceitos: 1) notícias; 2) crianças e jovens. Relativamente ao segundo grupo, recorreu-se à trucagem (através 
do asterisco) para pesquisar variantes de palavras, permitindo alcançar variações das mesmas, em particular formas plurais. Os operadores booleanos AND e OR foram usados para relacionar os conceitos, tendo sido realizados testes para obter os melhores resultados com a ajuda de uma especialista em pesquisa em bibliotecas digitais da Universidade do Minho. Com a fórmula escolhida, pretendeu-se encontrar um crivo que fosse lato, mas não em excesso, ou seja, que permitisse encontrar o máximo de resultados relevantes, mas não devolver resultados irrelevantes em demasia, o que normalmente sucede quando se acrescentam mais termos de pesquisa (Campbell et al., 2018). A fórmula encontrada foi a seguinte: "news AND child* OR adolesc* OR young* OR teen* OR youth *".

A pesquisa foi aplicada ao campo "AB Abstract or Author-Supllied Abstract", sendo ainda refinada a partir das possibilidades oferecidas pelas ferramentas de pesquisa avançada. Os resultados foram restringidos quanto a: tipo de revistas, tendo-se optado por limitar a pesquisa a revistas científicas (revistas por pares); tipo de publicação, foram considerados apenas "academic journals". Não se colocaram restrições face ao tipo de documento, dado que a realização de testes prévios tinha mostrado que, selecionando apenas "articles", os estudos de caso ficavam fora da pesquisa. Por fim, aceitaram-se resultados em cinco idiomas: espanhol, francês, inglês, italiano e português. Também não foram feitas restrições temporais, já que uma das questões de pesquisa se prende justamente com a evolução ao longo do tempo da investigação feita em torno do tema em análise.

A pesquisa foi realizada no dia 2 de dezembro de 2019, tendo-se obtido 777 resultados. Para estabelecer uma comparação, replicou-se a pesquisa (com os mesmos termos, mas com filtros semelhantes, já que as pesquisas nas diversas bases de dados não oferecem exatamente as mesmas possibilidades) nas seguintes plataformas científicas.

\begin{tabular}{ll}
\hline \multicolumn{1}{c}{ Plataformas } & \multicolumn{1}{c}{ N $^{\mathbf{0}}$ DE REFERÊNCIAS } \\
\hline B-On & 2189 \\
\hline Eric & 156 \\
\hline Google Scholar & 3480 \\
\hline Scopus & 2189 \\
\hline
\end{tabular}

Tabela 1: Ocorrência dos termos de pesquisa em várias bases de dados

Como se pode observar, à exceção da base de dados especializada em Educação, a ERIC, as restantes devolvem um número muito superior de resultados, cuja análise implicaria uma disponibilidade muito superior de tempo.

\section{Processo de inclusão E eXCLUSÃo de ARTigos}

Relativamente às referências conseguidas através da pesquisa na Communication Abstracts, o passo seguinte consistiu na leitura de todos os títulos e resumos dos 777 artigos, com o intuito de fazer uma seleção que correspondesse aos critérios de inclusão. 
Seguindo o conselho de Petersen e Ali (2011), procurou-se estabelecer critérios claros, objetivos e fáceis de verificar, sem necessidade de interpretação. Revelou-se mais fácil, para compreender se um artigo cumpria ou não os critérios pretendidos, estabelecer alguns sob a forma de perguntas. Em nome de uma maior transparência que, como realçam Vom Brocke et al. (2009), deve ser garantida para permitir aos leitores avaliarem melhor a revisão, optou-se por especificar algumas situações de exclusão, que poderiam suscitar maior dúvida caso alguém pretendesse replicar este trabalho'. Apresenta-se, em seguida, o protocolo que orientou a fase de inclusão ou exclusão das referências encontradas.

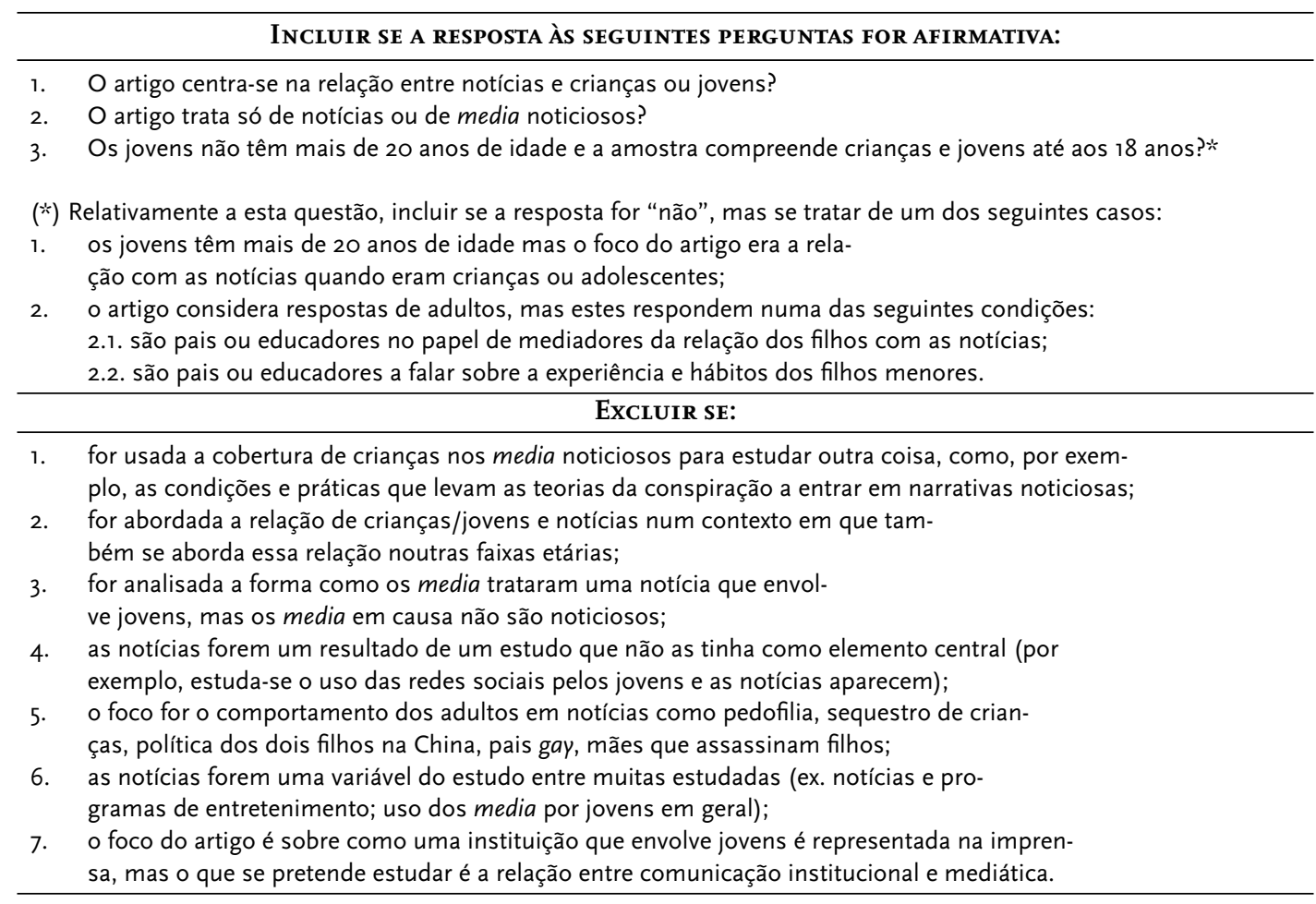

Tabela 2: Protocolo que orientou a fase de inclusão ou exclusão das referências encontradas

O processo de seleção dos artigos é, provavelmente, a tarefa mais exigente e que consome mais tempo num processo de RSL. Para a simplificar, optou-se-por realizar esta etapa por fases.

Começou-se por ler todos os resumos excluindo aqueles que claramente não cumpriam os critérios para integrarem a amostra e selecionando os que não ofereciam dúvidas quanto à sua inclusão. Nesta fase, constatou-se que havia referências duplicadas (o mesmo artigo publicado em mais do que uma língua ou duplicado). Para estes doze casos, manteve-se uma versão e excluiu-se outra, num total de seis artigos. Encontraram-se, ainda, referências que não correspondiam a artigos e que foram, por isso, excluídas,

\footnotetext{
' Tal como advertiu a leitura de artigos sobre RSL, também neste estudo foi inevitável adaptar os critérios de inclusão e exclusão ao longo do processo de seleção, pois, como notam Staples e Niazi (2007), o investigador vai obtendo um maior conhecimento do tema ao ler os artigos, o que lhe permite melhorar os critérios iniciais de seleção.
} 
como editoriais ou índices. Assim, foram eliminadas 36 referências, passando a amostra de 777 para 741.

Num segundo momento leram-se os resumos dos artigos cuja seleção não se afigurou tão evidente. Em vários casos, a leitura dos resumos não disponibilizou os dados necessários para saber se o artigo cumpria os critérios de inclusão. A maior parte das vezes esta situação relacionou-se com a idade dos sujeitos estudados, que não era especificada. Tal obrigou a uma consulta do texto integral dos artigos e, por vezes, foi mesmo necessário escrever aos autores. Esclarecidas as dúvidas foi possível concluir o processo de inclusão/exclusão, que conduziu a 158 resultados apurados. Porém, alertados por Staples e Niazi (2007) que, numa RSL que conduziram, identificaram artigos escritos pelos mesmos autores que reportavam os mesmos resultados acerca de um mesmo estudo e só divergiam ligeiramente na estrutura, fez-se ainda um exercício de comparar todos os artigos assinados pelo(s) mesmo(s) autor(es). Este processo levou a que fossem excluídos mais doze artigos. Finda esta etapa chegou-se aos 146 artigos que constituem a amostra.

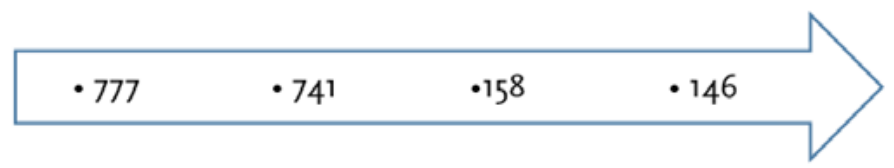

Figura 2: Evolução do número que constitui a amostra passadas as diferentes etapas de seleção descritas

Na seguinte tabela, pode observar-se a informação que procurámos obter a partir dos resumos de cada um dos artigos.

\begin{tabular}{|c|c|}
\hline SOBRE OS ARTIGOS & $\begin{array}{l}\text { - Ano de publicação } \\
\text { - Nome do jornal ou revista } \\
\text { - Área temática }\end{array}$ \\
\hline SOBRE OS AUTORES & $\begin{array}{l}\text { - Nome } \\
\text { - Filiação: nacionalidade } \\
\text { - Artigos assinados em conjunto por autores de diferentes países }\end{array}$ \\
\hline SOBRE OS ESTUDOS & $\begin{array}{l}\text { - Público-alvo } \\
\text { - Media estudado } \\
\text { - Tipo de estudo } \\
\text { - Metodologia adotada }\end{array}$ \\
\hline
\end{tabular}

Tabela 3: Quadro ilustrativo da informação a obter a partir da leitura dos resumos

\section{ANÁLISE DOS RESULTADOS}

\section{EVOLUÇÃo do NÚMERO DE ARTIGOS PUBLICADOS}

O Gráfico 1 ilustra a evolução do número de artigos publicados ao longo dos anos (1978-2019). Até 2003 é muito reduzido o número de publicações encontradas, variando entre nenhum e três artigos. Entre 2004 e 2016, o número de publicações, embora oscilante, sobe ligeiramente, aproximando-se, regra geral, já da meia dezena por ano, com 
uma clara exceção em 2011 - ano em que esse número ultrapassa pela primeira vez a dezena, situando-se nos 11 artigos. Algo que só volta a acontecer seis anos mais tarde, em 2017 e em 2019, com uma ligeira quebra em 2018. Nos últimos cinco anos nota-se uma tendência de crescimento do número de artigos mais sustentada, ficando sempre acima dos sete artigos por ano. Este aumento mais recente do número de publicações pode significar uma maior atenção dada por parte dos investigadores a esta temática, também na sequência das preocupações em torno das designadas fake news e do conceito de pós-verdade. O aumento do número de artigos verificado a partir de 2004 pode dever-se ao facto a que já atrás se aludiu, de as tecnologias da informação terem facilitado a publicação de artigos científicos².

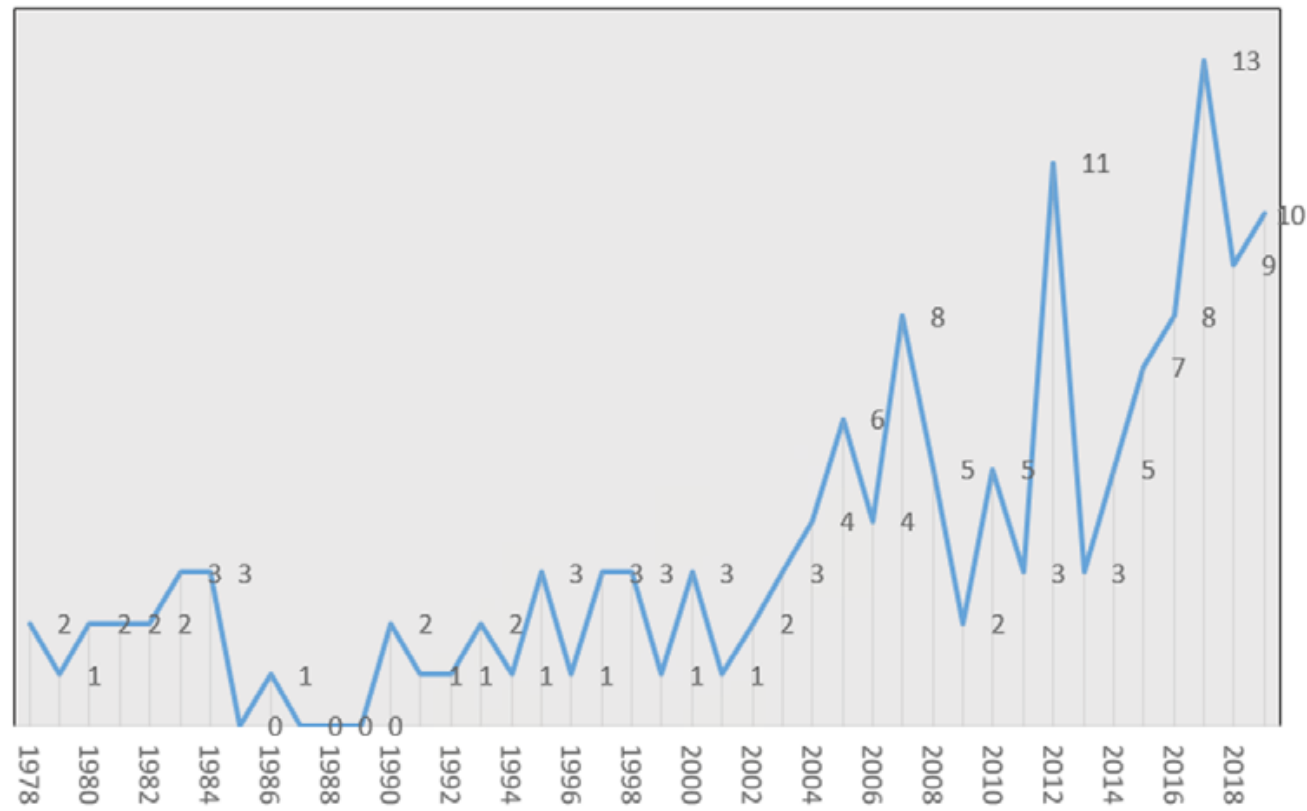

Gráfico 1: Evolução do número de artigos publicado por ano ao longo do tempo (1978-2019)

\section{PublicaÇão de ARTigos Por ReVista Científica}

$\mathrm{Na}$ tabela seguinte pode observar-se quais as revistas que mais artigos publicaram em torno da temática crianças, jovens e notícias, informação que se revela de utilidade para saber onde encontrar pesquisas já realizadas sobre o tema em apreço e onde poderá ser importante dar a conhecer o trabalho realizado.

\footnotetext{
${ }^{2}$ Na página da Communication Abstracts não é possível encontrar informação sobre a evolução do número de artigos que a base veio a disponibilizar ao longo dos anos, que nos permitiria estabelecer um termo de comparação com o gráfico que aqui é apresentado.
} 


\begin{tabular}{lll}
\hline \multicolumn{1}{c}{ ReVISTAS CIENTÍFICAS } & FREQUÊNCIA & $\%$ \\
\hline Journal of Children Q Media & 15 & 10,2 \\
\hline Communication Research & 10 & 6,9 \\
\hline Journalism Studies & 8 & 5,5 \\
\hline Journalism Quarterly & 6 & 4,1 \\
\hline Journalism & 5 & 3,4 \\
\hline Communication Research Reports & 4 & 2,7 \\
\hline Journal of Health Communication & 4 & 2,7 \\
\hline Journalism Q Mass Communication Quarterly & 4 & 2,7 \\
\hline Journal of Broadcasting Q Electronic Media & 3 & 2,1 \\
\hline Journal of Educational Media & 3 & 2,1 \\
\hline Mass Communication Q Society & 3 & 2,1 \\
\hline Newspaper Research Journal & 3 & 2,1 \\
\hline
\end{tabular}

Os 146 artigos que compõem a amostra encontram-se distribuídos por 70 publicações, o que ilustra a dispersão dos artigos desta temática e reforça a importância e a utilidade das bases de dados digitais, que vieram facilitar aos investigadores o acesso a trabalhos do seu interesse. Conforme ilustrado na tabela acima, as revistas com três ou mais publicações são 12 e nelas estão publicados 68 artigos, o que equivale a $46,3 \%$ do total. Os restantes 68 artigos (53,7\%) surgem em revistas com apenas uma ou duas publicações. Note-se que cinco revistas reúnem 30\% do total de referências.

O lugar de topo ocupado pelo Journal of Children and Media, fundado em 2007 e atualmente publicado pela Taylor \& Francis Online, é compreensível, já que se trata de uma publicação interdisciplinar dedicada à discussão da presença dos media na vida de crianças e adolescentes, dando atenção a três áreas complementares: crianças como consumidores de media, representações de crianças nos media e organizações/ produções de media para crianças ou por crianças. A revista, com revisão por pares e quatro edições por ano, acolhe estudos de tradições teóricas e empíricas de académicos e profissionais de todo o mundo. Como se pode ler no seu site ${ }^{3}$, pretende ser um fórum a nível internacional para discutir as questões atrás referidas, tanto em contextos locais, como nacionais ou globais.

A revista Communication Research, que ocupa o segundo lugar, conta já 45 anos de vida e é publicada pela SAGE Publishing. Tal como o Journal of Children and Media nasceu nos Estados Unidos, mas o seu caráter é mais abrangente, uma vez que cobre todo o campo dos estudos da Comunicação, publicando artigos que, conforme se pode ler no site da publicação, "exploram os processos, antecedentes e consequências da comunicação em larga escala nos sistemas sociais"4.

\footnotetext{
${ }^{3}$ Ver https://www.tandfonline.com/toc/rchm2o/current

${ }_{4}$ Retirado de https://journals.sagepub.com/home/crx
} 
$\mathrm{Na}$ análise das publicações, as revistas científicas sobre Jornalismo, Comunicação e Media constituem, sem surpresa, a maioria, mas é curioso notar a presença de sete revistas cujo foco central é a Educação.

\section{ÂNGULOS DE ABORDAGEM DA INVESTIGAÇÃo}

Uma das questões centrais de investigação desta RSL prendia-se com perceber, a partir da leitura dos resumos, quais tinham sido os prismas mais estudados sobre a relação entre notícias e crianças ou jovens. Assim, os artigos foram agrupados inicialmente por três categorias, tradicionais nos estudos da comunicação: estudos de receção e efeitos; estudos sobre a produção; e estudos sobre a representação. Outras três categorias emergiram da análise dos títulos e resumos dos artigos: impacto das notícias na participação ou socialização política; impacto da mediação parental; e preocupações éticas dos jornalistas na cobertura de notícias que envolvem crianças. Os 146 artigos foram, então, subdivididos pelas seis categorias ${ }^{5}$, cujos critérios de inclusão se especificam na tabela seguinte.

\begin{tabular}{ll}
\hline \multicolumn{1}{c}{ CATEGORIA } & \multicolumn{1}{c}{ DESCRIÇão } \\
\hline Representação & $\begin{array}{l}\text { Como os media retratam algum tema relacionado com crianças ou } \\
\text { jovens (sexualidade, delinquência, autismo, sexo adolescente...) } \\
\text { em geral ou em particular (Malala Yousafzai, por exemplo). }\end{array}$ \\
\hline $\begin{array}{l}\text { Impacto das notícias na partici- } \\
\text { pação ou socialização política }\end{array}$ & $\begin{array}{l}\text { Relação entre a leitura de notícias e a participação cidadã/políti- } \\
\text { ca/ambiental ou socialização política de crianças ou jovens. }\end{array}$ \\
\hline \multirow{2}{*}{ Impacto da mediação parental } & $\begin{array}{l}\text { Se existe mediação, como é feita; como influencia o in- } \\
\text { teresse por notícias por parte dos mais novos. }\end{array}$ \\
\hline \multirow{2}{*}{ Receção e efeitos } & $\begin{array}{l}\text { Como as crianças ou jovens consomem e/ou recebem as notícias; que } \\
\text { competências têm em literacia para as notícias, pensamento crítico } \\
\text { face a elas ou habilidades para avaliarem a credibilidade das notícias; } \\
\text { como um tipo específico de notícias pode afetar crianças e jovens. }\end{array}$ \\
\hline Produção & $\begin{array}{l}\text { Estudos sobre produção de notícias para crianças ou jovens ou como } \\
\text { essas notícias devem ser para os atrair. Também se incluíram ar- } \\
\text { tigos sobre a produção de notícias por crianças ou jovens. }\end{array}$ \\
\hline \multirow{2}{*}{$\begin{array}{l}\text { Preocupações éticas dos jornalistas } \\
\text { Sobre cobertura de notícias que envolvem crianças; como os jornalistas adultos } \\
\text { consideram as crianças ao fazer cobertura de eventos em que elas aparecem. }\end{array}$}
\end{tabular}

Tabela 5: Explicitação das categorias de enquadramento

A distribuição da amostra pelas categorias pode observar-se no gráfico seguinte.

\footnotetext{
${ }_{5}^{5}$ Quando um artigo podia integrar mais do que uma categoria, foi escolhida aquela que se considerou ser a dominante. Relativamente à categoria "preocupações éticas dos jornalistas" é de referir que os artigos científicos encontrados debruçam-se sobre as preocupações éticas dos jornalistas e não sobre preocupações éticas levantadas pelos investigadores em decorrência da cobertura noticiosa feita pelos jornalistas.
} 

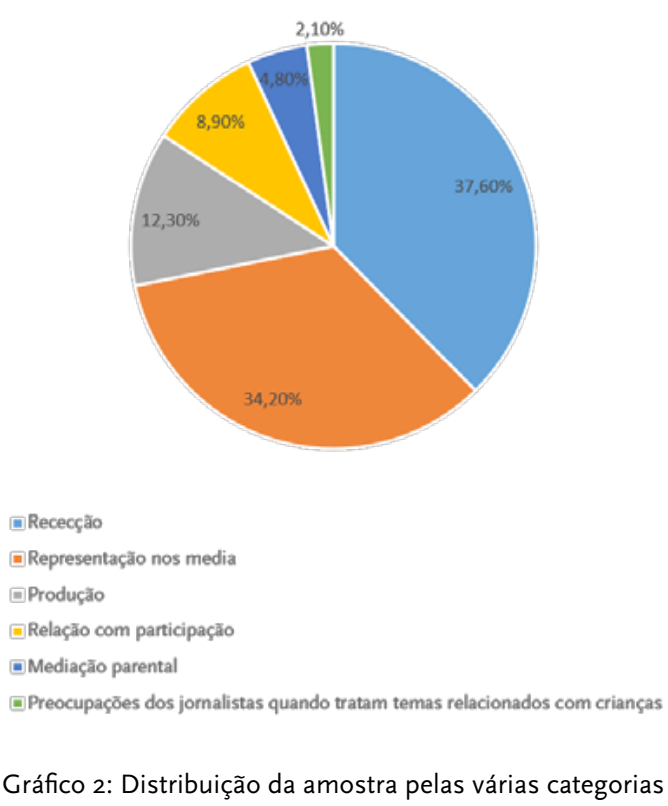

Como se pode inferir da leitura do gráfico, há duas abordagens que dominam a pesquisa nesta área: estudos de receção (representam 37,6\% do total, equivalentes a 55 artigos); a curta distância do primeiro, estudos sobre como determinados acontecimentos relacionados com crianças e jovens foram cobertos pela imprensa $34,2 \%$, correspondentes a 50 artigos). Juntas, estas abordagens totalizam mais de dois terços do total da amostra ( $71,8 \%)$, sendo portanto as categorias que mais interesse têm despertado aos investigadores.

Cada uma destas duas categorias merece um olhar mais atento.

Os estudos de receção marcam presença ao longo de todo o período estudado, de 1978 a 2019.

Um pouco mais de um quinto $(21,3 \%)$ do total preocupou-se em compreender como os jovens recebem e lidam com notícias tristes ou violentas, denotando, assim, uma preocupação com os efeitos por parte dos investigadores. Nesta subcategoria enquadraram-se onze artigos, um número próximo ao de artigos que integram a categoria de impacto na participação e socialização política (13). Face a estes dois conjuntos de artigos há uma outra comparação que se pode estabelecer: os estudos centrados nos efeitos surgem distribuídos no tempo entre 1993 e 2019. Já os estudos centrados no impacto das notícias na participação dos mais jovens concentram-se em dois momentos, separados entre si três décadas: há registo destes artigos entre 1981 e 1984, mas depois só voltam a surgir entre 2014 e 2019.

Relativamente aos 50 artigos que entram na categoria designada por representação, a maioria (32) dos temas que motivou este tipo de investigação diz respeito a acontecimentos negativos, como guerras, sequestros de crianças, violência ou delinquência juvenil, abuso sexual. Seis artigos centram-se na relação entre as crianças e a internet, dos quais quatro abordam problemáticas como o cyberbullying, o sexting ou os riscos online. Há oito artigos que se relacionam com questões (quase sempre problemas) de saúde, como obesidade, cancro infantil ou autismo. Este centrar da investigação em aspetos 
negativos parece mostrar como os media têm a capacidade de marcar a agenda, mesmo de quem os tem como objeto de estudo, uma vez que várias investigações têm mostrado que a abordagem da população infantojuvenil pela imprensa é marcada, justamente, por imagens negativas, o que também se verifica em Portugal (Brites, 2013; Ponte, 2009).

Ainda na categoria da representação, sobressai uma preocupação dos investigadores com grupos mais vulneráveis: quatro artigos são sobre crianças imigrantes ou refugiadas, outros quatro sobre minorias étnicas. Jovens que vivem nos subúrbios, crianças multiculturais ou transgénero motivaram também investigações, tal como crianças-estrela (Malala Yousafzai ou os protagonistas do filme Slumdog Millionaire, 2008). Olhando para o período temporal em que estes artigos foram produzidos, nota-se que os estudos de representação só começam a ser uma tendência na investigação nesta área a partir de finais dos anos 90 do século passado. Todos os artigos, à exceção de um, estão datados entre 1998 e 2019.

Prosseguindo a leitura do gráfico, as quatro restantes categorias correspondem a pouco mais de um quarto da amostra: $28,1 \%$ (41 artigos).

A maior parcela centra-se na produção de notícias para ou por crianças e jovens (12,3\%, correspondente a 18 artigos). Apenas uma peça se foca em jornalismo escolar: a grande maioria $(67 \%)$ analisa jornais ou noticiários de televisão dirigidos à infância ou juventude em várias partes do mundo e o programa da BBC Newsround é analisado em mais do que um artigo.

A seguir às já referidas publicações sobre o impacto das notícias na participação e socialização (8,9\%, com 13 artigos), a receber pouco interesse por parte da academia, ficam o estudo da mediação parental (4,8\%, com sete artigos) e das preocupações éticas dos jornalistas face ao tratamento de crianças e jovens nas notícias ( $2,1 \%$, com três artigos).

\section{META-ANÁLISE SOBRE OS AUTORES}

Outra das questões de investigação pretendia identificar os investigadores com mais trabalhos publicados neste tema, com o intuito de chegar a bibliografia que não tivesse sido encontrada pela presente RSL e de encontrar contactos para possíveis parceiros de investigação. Para obter este dado, optou-se por seguir um sistema de pontuação, uma vez que não parecia rigoroso comparar apenas por número de artigos, sem ter em consideração se se tratava de primeiros ou segundos (ou mais) autores ${ }^{6}$.

Apesar de os Estados Unidos serem o país que tem, de longe, o maior número de trabalhos publicado neste domínio, os investigadores europeus têm uma presença muito significativa entre os que mais artigos publicam neste campo, com uma diferença mínima a favor dos estado-unidenses (de nove para sete autores).

$\mathrm{Na}$ Tabela 6, pode constatar-se que, embora à cabeça estejam dois homens, as mulheres estão em larga maioria. Dafna Lemish notava isso no balanço de 13 anos como

\footnotetext{
${ }^{6}$ Optou-se por atribuir ao investigador dois pontos por cada artigo de que fosse primeiro autor e um ponto por cada artigo de que fosse coautor. Deste modo, por exemplo, dois autores com dois artigos publicados, um com dois como primeiro autor e outro com dois como coautor, não obtinham a mesma pontuação.
} 
editora do Journal of Children and Media: o campo de estudo das crianças e dos media continuava dominado pelo sexo feminino, o que não a surpreendia "enquanto a esfera privada da família e o bem-estar das crianças, sua educação e alfabetização forem percebidas como território das mulheres - seja em residências individuais, instituições públicas ou campos acadêmicos" (Lemish, 2019, p. 120).

O investigador que mais pontos obteve nesta escala de autores com mais publicações é sueco. Adam Shehata é professor associado do departamento de Jornalismo, Media e Comunicação da Universidade de Gotemburgo e assina quatro artigos, três deles como primeiro autor. Neste ranking individual, surgem, de seguida, dois autores norte-americanos com três artigos como primeiro autor cada: Charles Atkin foi professor catedrático na Universidade de Wisconsin, no Departamento de Comunicação, a que também preside; Regina Marchi, professora associada de Jornalismo e Estudos de Media na Rutgers School of Communication and Information, em New Jersey, trabalha na interseção entre os media, a cultura e a política, focando comunidades desprivilegiadas, entre as quais se contam as crianças - em 2017 publicou em coautoria o livro Young people and the future of news: social media and the rise of connective journalism, pela Cambridge University Press.

Com cinco pontos cada, surgem depois três académicas holandesas: Moniek Buijzen e Mariska Kleemans, ambas da Universidade de Radboud (que, como a Universidade de Amesterdão, tem um considerável número de investigadores a assinar artigos, como autores ou coautores, nesta amostra: nove no caso de Radboud, oito no caso de Amesterdão); Juliette Walma Van Der Molen, da Universidade de Twent. Das três, a que parece desenvolver um trabalho mais centrado na temática em questão é Kleemans, cuja pesquisa tem por objetivo investigar como o vínculo entre crianças e notícias pode ser aprimorado: "como as crianças se podem envolver mais com as notícias e como as notícias podem inspirá-las a envolver-se mais com a sociedade"7. Kleemans debruça-se ainda sobre como as notícias negativas devem ser apresentadas às crianças. O trabalho de Buijzen vai mais no sentido de aplicar o conhecimento científico da comunicação para melhorar o bem-estar dos jovens, e Van Der Molen aprofunda a forma como os jovens aprendem a partir de diferentes media. ${ }^{8}$

\begin{tabular}{llll}
\hline \multicolumn{1}{c}{ Nome } & \multicolumn{1}{c}{ PAÍ́s } & N $^{\mathbf{0}}$ DE PONTOS & N $^{\mathbf{0}}$ DE ARTIGOS \\
\hline Shehata, Adam & Suécia & 7 & 4 \\
\hline Atkin, Charles K. & EUA & 6 & 3 \\
\hline Marchi, Regina & EUA & 6 & 3 \\
\hline Buijzen, Moniek & Holanda & 5 & 4 \\
\hline Kleemans, Mariska & Holanda & 5 & 3 \\
\hline Van Der Molen, Juliette Walma & Holanda & 5 & 3 \\
\hline
\end{tabular}

\footnotetext{
7 Retirado de https://www.ru.nl/english/people/kleemans-m/

${ }^{8}$ Dois dos autores que assinaram artigos encontrados na presente RSL não apresentavam filiação nem foi possível chegar a ela a partir da pesquisa dos seus nomes na internet.
} 


\begin{tabular}{llll}
\hline Cairns, E. & Irlanda do Norte & 4 & 2 \\
\hline Drew, Dan G. & EUA & 4 & 2 \\
\hline Edgerly, Stephanie & EUA & 4 & 2 \\
\hline Mathews, Julian & Inglaterra & 4 & 2 \\
\hline Moeller, Judith & Holanda & 4 & 2 \\
\hline Riddle, Karyn & EUA & 4 & 2 \\
\hline Smith, Stacy L. & EUA & 4 & 2 \\
\hline Wanta, Wayne & EUA & 4 & 2 \\
\hline Wilson, Barbara J. & EUA & 4 & 3 \\
\hline Worthington, Nancy & EUA & 4 & 2 \\
\hline Sem filiação & - & - & 2 \\
\hline
\end{tabular}

Tabela 6: Lista dos autores com mais artigos publicados

Atentando nos países com maior número de artigos publicados (pela nacionalidade do primeiro autor), os Estados Unidos da América destacam-se, com metade do total. A seguir estão a Holanda, com 9,6\% e a Inglaterra, com 6,8\%. Somando o número de artigos escritos que tinham um europeu como primeiro autor, a percentagem fica ainda aquém da alcançada pelos EUA. (31,5\%). É um convite à reflexão o facto de na lista de 24 países representados na amostra (são 22 se se contar apenas os primeiros autores), constarem vários territórios marcados por uma história de violência (a nível interno ou com territórios vizinhos) ou de forte repressão. Exemplos disso são Israel, Palestina, Irlanda do Norte, Coreia do Sul, Turquia, Chile, Roménia e Taiwan que representam um terço dos países. Entre 1978 e 1991 (inclusive), os 19 artigos publicados e reunidos na base de dados da Communication Abstracts sobre este tema são de investigadores radicados em três países: EUA (14), Israel (três) e Irlanda do Norte (dois).

\begin{tabular}{|c|c|c|}
\hline PAÍSES & $\mathrm{N}^{\circ}$ DE ARTIGOS (1 ${ }^{\circ}$ AUTOR) & $\%$ \\
\hline EUA & 73 & 50 \\
\hline Holanda & 14 & 9,6 \\
\hline Inglaterra & 10 & 6,8 \\
\hline Austrália & 6 & 4,1 \\
\hline Bélgica & 6 & 4,1 \\
\hline Suécia & 6 & 4,1 \\
\hline Israel & 5 & 3,4 \\
\hline Canadá & 4 & 2,7 \\
\hline Irlanda do Norte & 3 & 2,1 \\
\hline Sem filiação & 2 & 1,4 \\
\hline
\end{tabular}

Tabela 7: Lista da nacionalidade (filiação) do primeiro autor 
Relativamente aos autores, foi também objetivo saber se tem havido trabalho conjunto entre investigadores de diferentes países e se realidades nacionais diferentes têm sido comparadas. Concluiu-se que poucos trabalhos cruzam mais do que uma realidade ou têm contributos de autores com enquadramentos geográficos e culturais diferentes. Registaram-se sete artigos escritos por investigadores de países diferentes (seis juntam autores de dois países; um junta autores de três países). Há, no entanto, nove artigos que se debruçam sobre realidades de mais do que um país (Brasil e Suécia; Coreia do Sul e Holanda; Índia e realidade internacional; Turquia, Marrocos e Flandres; Itália, Portugal e Espanha; Londres e Nova Iorque; EUA, Reino Unido, Qatar e Jerusalém; 14 países europeus) e um artigo que compara Judeus e Árabes em Israel. Como frisa Barnhurst (2000), contrastar grupos que cresceram em diferentes realidades noticiosas permite a procura de padrões comuns, contribuindo para perceber, por exemplo, se há uma cultura de geração que atravesse fronteiras culturais ou nacionais. Por outro lado, acrescenta o mesmo autor, as diferenças podem indicar contextos diferentes, com políticas alternativas que importa avaliar. De uma forma ou outra, a comparação permite construir uma teoria fundamentada.

Relativamente às nacionalidades, constata-se que alguns países se interessam mais por determinadas áreas de investigação. Isso é notório, no caso da Suécia, onde quatro dos seis artigos se inserem na categoria que avalia o impacto das notícias na participação e socialização política. Dos 10 artigos que têm como primeiro autor um inglês, três (30\%) enquadram-se na categoria produção, a que não será indiferente o facto de a estação de televisão britânica de serviço público, BBC, produzir o mais antigo noticiário televisivo para crianças do mundo, o Newsround.

\section{META-ANÁLISE SOBRE OS ARTIGOS}

Relativamente aos trabalhos publicados, foi possível verificar que é bastante equilibrada a atenção dada a crianças e a jovens: 68 artigos centraram a sua pesquisa nas primeiras e 67 nos segundos. Houve ainda oito artigos que focaram os dois grupos indistintamente e três investigações que se centraram em bebés (estudos de representação). No caso dos resumos que mencionavam as idades estudadas, as crianças eram consideradas em faixas que oscilavam entre os cinco e os 13 anos de idades e os jovens (ou adolescentes) em intervalos que iam entre os 12 e os 19 anos. Foi ainda possível observar que os artigos que investigaram o impacto das notícias na participação ou socialização política se centraram na sua esmagadora maioria em jovens e que as investigações sobre a forma como as crianças recebem notícias negativas se voltaram para crianças.

Quando a análise se debruçou sobre os meios estudados, os resultados são os que se apresentam na Tabela 8. 


\begin{tabular}{|c|c|c|}
\hline MEIO OU MEDIA & ARTIGOS & $\%$ \\
\hline Nenhum meio específico: jornalismo e notícias em geral & 49 & 33,6 \\
\hline Televisão & 45 & 30,8 \\
\hline Jornais & 31 & 21,2 \\
\hline Notícias online & 8 & 5,5 \\
\hline Televisão, rádio e imprensa escrita & 4 & 2,7 \\
\hline Imprensa tradicional e online & 3 & 2,1 \\
\hline Revistas & 2 & 1,4 \\
\hline Televisão e jornais & 2 & 1,4 \\
\hline Rádio & 1 & 0,7 \\
\hline Televisão e rádio & 1 & 0,7 \\
\hline
\end{tabular}

Tabela 8: Medium ou conjunto de meios mais estudados

Como se verifica na Tabela 8, muitos artigos não se fixaram em nenhum meio específico, abordando as notícias em geral. Entre aqueles que se focaram num meio, a televisão foi o que mais motivou o interesse dos investigadores, seguida pelos jornais. A rádio tem apenas um artigo em que é alvo de análise de forma isolada. O meio digital já começa a ser alvo de estudo. O primeiro artigo que considera as notícias online para crianças data de 2010, correspondendo sensivelmente ao período em que o número de estudos sobre a televisão começa a diminuir.

Relativamente às metodologias utilizadas, não foi possível elaborar uma análise estatística uma vez que nem todos os resumos forneciam informações claras a este nível. Foi, no entanto, possível constatar que a esmagadora maioria dos artigos publicados neste domínio se baseia em estudos empíricos, que se servem tanto de metodologias qualitativas como quantitativas. Identificou-se apenas um único estudo baseado numa experiência de intervenção e os artigos que constituíam uma reflexão teórica não foram além da meia dezena.

Por fim, e seguindo o exemplo de Ramos, Faria e Faria (2014) fez-se uma nuvem de palavras importando para a ferramenta WordClouds ${ }^{9}$ todas as palavras-chave indicadas pelos autores dos vários artigos (48 autores não forneceram palavras-chave, razão pela qual esta nuvem é feita apenas com base nas palavras-chave fornecidas pelos autores de 98 artigos $^{10}$ ).

A Figura 3 permite constatar que as palavras-chave a que se recorreu para fazer a pesquisa se revelaram adequadas e que a nuvem, no seu conjunto, ilustra alguns dos resultados alcançados neste estudo. Além do destaque dado às palavras que se relacionam com a área da pesquisa (notícias e crianças e/ou jovens), encontram-se realçadas palavras que identificam todas as categorias identificadas a partir da análise dos resumos: receção/efeitos (audience, effects); representação e produção (analysis, content, discourse, framing); impacto da mediação parental (mediation); impacto na participação ou

\footnotetext{
9 Ver https://www.wordclouds.com/

${ }^{10}$ As palavras-chave que estavam em letra maiúscula foram colocadas em minúscula para que, na nuvem, surgissem uma só vez, caso contrário, o programa assume-as como palavras diferentes, dando origem a duas entradas e não permitindo dar a dimensão exata da frequência de determinada palavra-chave.
} 
socialização política (political, social, socialization); preocupações éticas dos jornalistas (ethics). Graças a esta ferramenta, os resultados obtidos poderão ser úteis na hora de escolher as palavras-chave que identificam investigações realizadas nesta área de estudo.

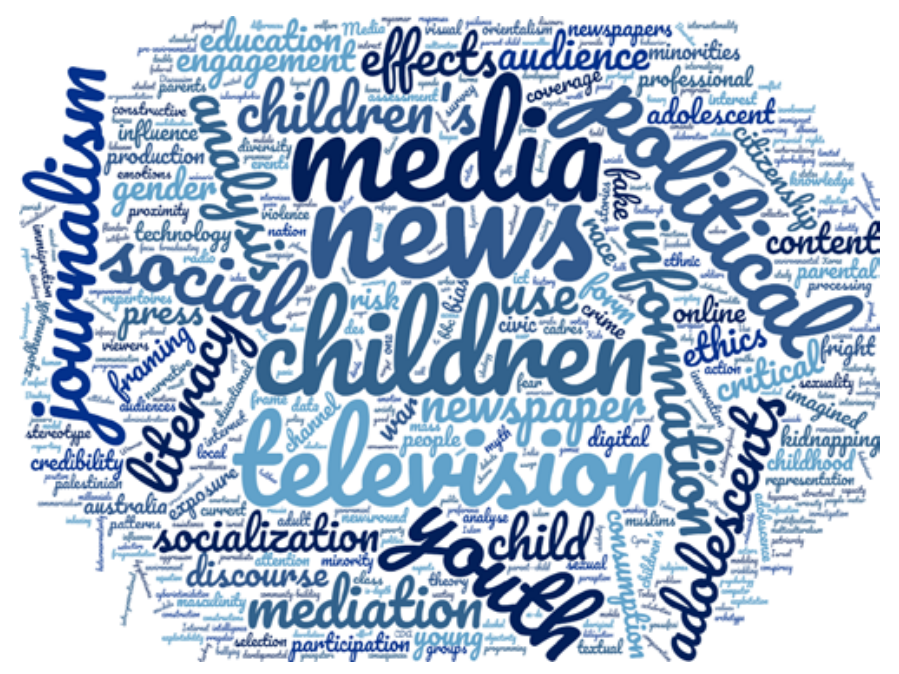

Figura 3: Mapa de frequências das palavras das palavras-chave

\section{CONSIDERAÇÕES FINAIS}

A técnica de revisão sistemática de literatura revelou-se uma ferramenta adequada ao objetivo de mapear e fazer uma meta-análise ao trabalho feito até ao momento em torno da relação entre crianças e/ou jovens e notícias. A visão de conjunto que se pretendia obter dificilmente teria sido conseguida fazendo uma revisão de literatura convencional. Considera-se, no entanto, que os dois tipos de revisão de literatura não se podem colocar, numa visão alternativa, mas sim complementar, nomeadamente no campo das Ciências Sociais, sob pena de sujeitar a investigação a um viés positivista. A RSL foi um importante passo inicial para, a partir daqui, se proceder a uma leitura crítica dos artigos na íntegra e, através deles, chegar a outros estudos e autores.

O facto de esta revisão se limitar a uma base de dados determina que estudos relevantes neste domínio não integrem esta amostra, além de que se cinge à área da Comunicação, pondendo não contemplar investigações de outros campos de estudo. O facto de a grande parte das revistas que integra a Communicatio Abstracts ser anglo-saxónica limita as referências disponíveis, pelo que será importante num trabalho futuro alargar a pesquisa a bases de dados que disponibilizem maior produção científica noutras línguas, nomeadamente, em língua portuguesa. A pesquisa por este tipo de bases de dados condiciona, ainda, o acesso a fontes documentais tão importantes como são os livros. Tendo presente estas limitações, considera-se, ainda assim, que foi um trabalho relevante, com o qual foi possível identificar as áreas mais estudadas - receção e representação - e mais negligenciadas - produção, impactos na participação, mediação parental e preocupações éticas dos jornalistas; os momentos em que o tema mereceu mais atenção, de 2011 até à atualidade; e as revistas que lhe deram mais 
destaque, com o Journal of Children and Media à cabeça. Percebeu-se que, embora os EUA apresentem metade dos artigos publicados neste âmbito, na lista dos autores que mais se dedicam ao tema há um equilíbrio entre norte-americanos e europeus e que a área interessa sobretudo a investigadoras (sexo feminino). A maioria dos artigos aborda notícias em geral. Quando os estudos se centram num meio apenas, a televisão é o mais estudado, sendo que, a partir de 2010 , os estudos sobre a televisão começam a decair e o online começa a despertar o interesse dos investigadores. Já quanto ao público-alvo, notou-se um equilíbrio no número de estudos que se centram só em crianças ou só em jovens. Relativamente à geografia das investigações, há ainda poucos estudos a cruzar realidades diferentes e um terço dos países que têm trabalhos publicados nesta área corresponde a territórios marcados por violência ou por uma história recente marcada por regimes políticos totalitários.

Terminando como se começou, esta RSL está longe de nos ter permitido conhecer o "gigante" a que aludimos no início, mas permitiu identificar-lhe os contornos. Conhecê-lo em profundidade será o passo que se segue na investigação.

\section{Agradecimentos}

Este estudo foi realizado no âmbito do projeto de doutoramento em Ciências da Comunicação, na Universidade do Minho, financiado pela Fundação para a Ciência e a Tecnologia através da bolsa com a referência BD/139388/2018.

Este trabalho é financiado por fundos nacionais através da FCT - Fundação para a Ciência e a Tecnologia, I.P., no âmbito do projeto UIDB/00736/2020. O Financiamento Plurianual do Centro de Estudos de Comunicação e Sociedade (UIDB/o0736/2020) apoiou a tradução do artigo.

\section{REFERÊNCIAS}

Barnhurst, K. G. (2000). Political engagement and the audience for news: lessons from Spain. Journalism Q Communication Monographs, 2(1), 6-61. https://doi.org/10.1177/152263790000200102

Best, P., Taylor, B., Manktelow, R. \& McQuilkin, J. (2014). Systematically retrieving research in the digital age: case study on the topic of social networking sites and young people's mental health. Journal of Information Science, 40(3), 346-356. https://doi.org/10.1177/0165551514521936

Boell, S. K. \& Cecez-Kecmanovic, D. (2015). On being 'systematic' in literature reviews in IS. Journal of Information Technology, 30, 161-173. https://doi.org/10.1057/jit.2014.26

Brites, M. J. (2013). Os jovens e a cidadania: a relevância do espaço mediático. Caleidoscópio, 10, 177-188

Buckingham, D. (1997). The making of citizens: pedagogy and address in children's television news. Journal of Educational Media, 23(2-3), 119-139. https://doi.org/10.1080/1358165970230203

Campbell, A., Taylor, B., Bates, J. \& O'Conner-Bones, U. (2018). Developing and applying a protocol for a systematic review in the Social Sciences. New Review of Academic Librarianship, 24(1), 1-22. https://doi. org/10.1080/13614533.2017.1281827 
Carter, C. \& Allan, S. (2005) Hearing their voices: young people, citizenship and online news. In A. Williams \& C. Thurlow (Eds.), Talking adolescence: perspectives on communication in the teenage years (pp. 73-90). Nova lorque: Peter Lang.

Carter, C., Messenger-Davies, M., Allan, S. \& Mendes, K. (2009). What do children want from BBC? Children's content and participatory environments in an age of citizen media. Cardiff: The Cardiff School of Journalism. Retirado de https://www.bbc.co.uk/blogs/knowledgeexchange/cardifftwo.pdf

Carver, J. C., Hassler, E., Hernandes, E. \& Kraft, N. A. (2013). Identifying barriers to the systematic literature review process. In Procedings of the International Symposium on Empirical Software Engineering and Measurement (pp 203-212). Washington, DC: IEEE. https://doi.org/10.1109/ESEM.2013.28

Cooper, H. M. (1988). Organizing knowledge syntheses: a taxonomy of literature reviews. Knowledge in Society, 1, 104-126.

English, P., Barnes, R., Fynes-Clinton, J. \& Stewart, L. (2019) Children's news in Australia: content for young readers in Crinkling News. Journal of Children and Media, 13(1), 73-88. https://doi.org/10.1080/17482798 .2018 .1547777

Fiolhais, C. (2011, 8 de dezembro). "Aos ombros de gigantes". [Post em blogue]. Retirado de http:// dererummundi.blogspot.com/2011/12/aos-ombros-de-gigantes.html

Hobbs, R., Cohn-Geltner, H. \& Landis, J. (2011). Views on the news. In C. Von Feilitzen; U. Carlsson \& C. Bucht (Eds.), New questions, new insights, new approaches (pp.43-55). Gotemburgo: Nordicom.

Lemish, D. (2019). "A room of our own": farewell comments on editing the Journal of Children and Media. Journal of Children and Media, 13(1), 116-126. https://doi.org/10.1080/17482798.2019.1557813

Pereira, L. (2011). Conceções de literacia digital nas políticas públicas - estudo a partir do Plano Tecnológico da Educação. Tese de doutoramento, Universidade do Minho, Braga, Portugal. Retirado de http:// repositorium.sdum.uminho.pt/handle/1822/19825

Pereira, S, Fillol, J. \& Silveira, P. (2015). Explicar o mundo às crianças: análise de espaços noticiosos dirigidos ao público infantojuvenil. In A. Barbalho \& L. Marôpo (Eds.), Infância, juventude e mídia: olhares lusobrasileiros (pp. 365-394). Fortaleza: EdUECE.

Petersen, K. \& Ali, N. B. (2011). Identifying strategies for study selection in systematic reviews and maps. In International Symposium on Empirical Software Engineering and Measurement (pp. 351-354). Banff: IEEE. https://doi.org/10.1109/ESEM.2011.46

Petticrew, M. \& Roberts, H. (2006). Systematic reviews in the Social Sciences: a practical guide. Oxford: Blackwell.

Ponte, C. (2009), Crianças e jovens em notícia. Lisboa: Livros Horizonte.

Ramalho, A. (2005). Redação de estudos e projetos de revisão sistemática com e sem metanálise. Coimbra: Formasau.

Ramos, A., Faria, P. M. \& Faria, A. (2014). Revisão sistemática da literatura: contributo para a inovação na investigação em Ciências da Educação. Revista Diálogo Educ., 14(41), 17-36. https://doi.org/10.7213/ dialogo.educ.14.041.DSo1

Silveira, P. (2019). Notícias televisivas e públicos infantis: o porquê da aposta em jornalismo segmentado para as crianças. Observatorio, 13(2), 48-67. https://doi.org/10.15847/obsOBS13220191467

Staples, M. \& Niazi, M. (2007). Experiences using systematic review guidelines. Journal of Systems and Software, 8o(9), 1425-1437. https://doi.org/10.1016/j.jss.2006.09.046 
Tranfield, D., Denyer, D. \& Smart, P. (2003). Towards a methodology for developing evidence-informed management knowledge by means of systematic review. British Journal of Management, 14(3), $207-222$. https://doi.org/10.1111/1467-8551.00375

Victor, L. (2008). Systematic reviewing in the Social Sciences: oucomes and explanation. Enquire, 1(1), 32-46. Retirado de http://prdb.pk/uploads/publications/1537169935393.pdf

Vom Brocke, J., Simons, A., Niehaves, B., Niehaves, B., Reimer, K., Plattfaut, R. \& Cleven, A. (2009). Reconstructing the giant: on the importance of rigour in documenting the literature search process. In ECIS 2009 Proceedings, 161. Retirado de http://aisel.aisnet.org/ecis2009/161

\section{NOTAS BIOGRÁFICAS}

Joana Fillol é estudante de doutoramento em Ciências da Comunicação no Centro de Estudo de Comunicação e Sociedade da Universidade do Minho, ao abrigo de uma bolsa da Fundação para a Ciência e Tecnologia. A sua pesquisa centra-se na relação entre crianças, jovens e notícias. Licenciada em Jornalismo pela Universidade de Coimbra, trabalhou vários anos na imprensa escrita e, em 2015, fundou um sítio de informação noticiosa para crianças e jovens (Jornalissimo.com). É colaboradora do MILobs - Observatório sobre Media, Informação e Literacia e coautora do programa de rádio Ouvido Crítico, emitido semanalmente na Antena 1

ORCID: https://orcid.org/o000-0002-8577-7809

Email: joanafillol@gmail.com

Morada: Centro de Estudos de Comunicação e Sociedade - Instituto de Ciências Sociais - Universidade do Minho, Campus de Gualtar, 4710-057 Braga, Portugal

Sara Pereira é Professora Associada do Departamento de Ciências da Comunicação e investigadora do Centro de Estudos de Comunicação e Sociedade (CECS) da Universidade do Minho. Tem como principais áreas de investigação as crianças, os jovens e os media, e a Literacia para os Media. Tem coordenado vários projetos nacionais e europeus e é autora de diversas publicações nestas áreas. Preside à secção Media Education Research da International Association for Media and Communication Research (IAMCR) desde julho de 2019. É cocoordenadora do MILobs - Observatório sobre Media, Informação e Literacia e coautora do programa de rádio Ouvido Crítico, emitido semanalmente na Antena 1 desde fevereiro de 2018.

ORCID: https://orcid.org/oooo-0002-9978-3847

Email: sarapereira@ics.uminho.pt

Morada: Centro de Estudos de Comunicação e Sociedade - Instituto de Ciências Sociais - Universidade do Minho, Campus de Gualtar, 4710-057 Braga, Portugal

* Submissão: 23/12/2019

* Aceitação: 09/04/2020 